\title{
PERBEDAAN DEBRIS INDEKS MENGGUNAKAN OBAT KUMUR ANTISEPTIK PADA MAHASISWA TINGKAT I JURUSAN KEPERAWATAN GIGI POLTEKKES KEMENKES MANADO
}

\author{
Vega Roosa Fione $e^{1,}$ Dewa Ari Winata \\ 1,2) Jurusan Keperawatan Gigi Poltekkes Kemenkes ManadoJl.RW Mongisidi Malalayang II Manado
}

Email : vegaroosa@poltekkesmanado.ac.id

\begin{abstract}
ABSTRAK
Kesehatan gigi dan mulut dapat dipengaruhi oleh faktor kebersihan gigi dan mulut yang buruk. Kebersih gigi dan mulut yang buruk menunjukan banyaknya sisa-sisa makanan (debris) yang melekat pada permukaan gigi. Upaya membersihkan gigi dan mulut pada umumnya adalah dengan cara menyikat gigi, menggunakan benang gigi, makan buah-buahan berserat dan berair dan berkumur-kumur dengan obat kumur. Obat kumur dipercaya membuat gigi lebih bersih dan melindunginya dari kerusakan serta penyakit. Penelitian ini bertujuan untuk mengetahui perbedaan debris indeks menggunakan obat kumur antiseptik dan memiliki manfaat secara teoritis dan praktis

Jenis penelitian ini menggunakan metode penelitian eksperimen dengan rancangan one group pretest-postest desingn, dimana ada kelompok perbandingan (kontrol). Cara pengambilan sampel yaitu dengan teknik total sampling dengan keriteria inklusi, dengan jumlah sampel 40 responden. Penelitian ini dilaksanakan pada bulan Juni 2017 dan berlokasi di Jurusan Keperawatan Gigi Poltekkes Kemenkes Manado.

Hasil penelitian menunjukan bahwa hasil uji paired sample $t$ Tes pada tingkat kemaknaan 95\% $(\alpha=0.05) p=0.000$ ( $p<0.05)$, sehingga ada pengaruh signifikan antara sebelum berkumur dengan obat kumur antiseptik dan sesudah berkumur dengan obat kumur antiseptik, terhadap penurunan debris indeks. Hal ini disebabkan karena obat kumur antiseptik mengandung thymol, mentol, eucaplytol, dan salicylate metil yang termasuk dalam minyak assential dapat berpengaruh terhadap penurunan debris indeks, maka disarankan sebaiknya menggunakan obat kumur antiseptik setelah menyikat gigi.
\end{abstract}

\section{Kata Kunci : Obat Kumur, Debris Indeks}

\begin{abstract}
Oral and dental health can be influenced by poor oral and dental hygiene factors. Bad teeth and mouth hygiene indicate the amount of food debris (debris) attached to the tooth surface. Efforts to clean teeth and mouth in general are by brushing teeth, using dental floss, eating fibrous and runny fruits and gargling with mouthwash. Mouthwash is believed to make teeth cleaner and protect them from damage and disease. This study aims to determine the differences in index debris using antiseptic mouthwash and has theoretical and practical benefits

This type of research uses experimental research methods with one group pretest-posttest design, where there is a comparison (control) group. The method of taking a sample is the total sampling technique with inclusion keriteria, with a total sample of 40 respondents. This research was conducted in June 2017 and is located in the Dental Nursing Department of the Ministry of Health, Manado.

The results showed that the results of paired sample t test at the 95\% significance level $(\alpha=0.05) \mathrm{p}$ $=0.000(\mathrm{p}<0.05)$, so there was a significant influence between before gargling with antiseptic mouthwash and after rinsing with antiseptic mouthwash, to a decrease in index debris. This is because antiseptic mouthwash containing thymol, menthol, eucaplytol, and methyl salicylate which are included in assential oil can affect the decrease in index debris, so it is recommended that you use an antiseptic mouthwash after brushing your teeth.
\end{abstract}

Key Words : Mouthwash, Debris Index 


\section{PENDAHULUAN}

Kesehatan gigi dan mulut dapat di pengaruhi oleh faktor seperti keadaan kebersihan gigi dan mulut yang buruk. Keadaan kebersihan gigi dan mulut yang buruk menyebabkan timbulnya berbagai masalah kesehatan gigi dan mulut. Faktor utama yang menyebabkan timbulnya masalah kesehatan gigi dan mulut adalah plak. Plak adalah lapisan lunak yang tidak berwarna, tidak dapat di lihat jelas dengan mata dan melekat erat pada permukaan gigi. ${ }^{1}$

Upaya membersihkan gigi dan mulut pada umumnya adalah dengan flossing, penyikatan gigi, dan penggunaan obat kumur. ${ }^{2}$ Obat kumur adalah cairan dengan rasa tertentu yang digunakan untuk bekumur-kumur setelah menyikat gigi atau flossing gigi, cairan ini dipercaya membuat gigi lebih bersih dan melindunginya dari kerusakan serta penyakit. Obat kumur dibedakan menjadi empat yaitu : obat kumur antiseptik, obat kumur fluoride, obat kumur kosmetik, dan obat kumur buatan sendiri. Obat kumur antiseptik ini dirancang untuk melawan plak dan melindungi gigi terhadap kerusakan kerusakan gigi. Ini juga menyamarkan bau mulut. ${ }^{3}$

Antiseptik merupakan zat yang digunakan untuk membunuh bakteri atau mikroorganisme. Obat kumur fluoride, mengandung fluoride yang menyerang asam di mulut yang menyebabkan kerusakan gigi. Obat kumur kosmetik. Tidak memiliki kemampuan untuk melawan plak hanya sekedar penyegar napas. Obat kumur buatan sendiri, dibuat di rumah menggunakan kombinasi garam dan air hangat untuk mengobati infeksi mulut atau efek dari ekstraksi gigi. ${ }^{4}$

Obat kumur ini mengandung bahan-bahan yang memiliki fungsi yang berbeda seperti : a). Zinc, kandungan ini mengontrol produksi gas yang menyebabkan bau mulut dan juga mencegah plak yang mengeras pada gigi,

Xilytol, kandungan ini dapat mengurangi tingkat plak bila digunakan secara teratur karena bisa melawan kuman. c) Fluoride, kandungan ini membantu memperkuat gigi dan mencegah terjadinya gigi berlubang. d) Baking soda, kandungan ini adalah pemutih gigi alami dan menjaga mulut tetap lembab dan bersih. Methol, kandungan ini bisa memberikan napas segar. ${ }^{3}$ Diantara berbagai kandungan obat kumur yang tersedia yang lebih efektif adalah yang mengandung xylitol. Xylitol adalah gula yang mengandung lima karbon alami yang terdapat pada pohon birch. Xylitol mengikat mulekul sukrosa dengan streptococcus mutans. Streptococcus mutans tidak dapat memfermentasi (mengurai) xylitol. Xylitol mengurangi streptococcus mutans dengan mengubah arah metabolisme dan meningkatkan remineralisasi serta membantu mencegah karies gigi. ${ }^{2}$ Meski begitu, hindarilah obat kumur yang mengandung alkohol karena bisa menyebabkan kelenjar ludah menjadi kering. jika air ludah berkurang maka akan meningkatkan resiko karies. Kondisi seperti ini dapat memicu plak dan bakteri yang bisa menyebabkan infeksi gusi, pendarahan dan bengkak, Untuk itu jika ingin mendapatkan manfaat yang lebih maksimal dari obat kumur sebaiknya hindarilah kandungan alkohol. ${ }^{5}$

Debris adalah bahan lunak dipermukaan gigi yang dapat merupakan plak, material alba, dan food debris. Plak gigi merupakan deposit lunak yang melekat erat pada permukaan gigi, terdiri atas mikroorganisme yang berkembang biak dalam suatu metrik intraseluler jika seseorang melalaikan kebersihan gigi dan mulutnya. Material alba suatu deposit lunak, berwarna kuning atau putih keabu-abuan yang melekat pada permukaan gigi, restorasi, kalkulus, dan gingival. Tidak mempunyai struktur yang spesifik serta mudah disingkirkan dengan 
semprotan air, akan tetapi untuk menyingkirkan dengan sempurna diperlukan pembersihan secara mekanis. Food debris adalah sisa-sisa makanan yang menempel dan melekat pada gigi. Debris berbeda dari plak dan material alba, debris lebih mudah dibersihkan. Kecepatan pembersihan debris makanan dari rongga mulut bervariasi menurut jenis makanan dan individunya. ${ }^{2}$ Food debris yang masih tertinggal didalam mulut merupakan sumber makanan untuk bakteri yang akan berkembang biak di dalam plak terutama makanan yang banyak mengandung gula. ${ }^{1}$ Tujuan penelitian ini untuk mengetahui perbedaan debris indeks menggunakan obat kumur antiseptik

\section{METODE}

Jenis penelitian ini menggunakan metode penelitian eksperimen dengan rancangan one group pretest-postest design, ada kelompok perbandingan (kontrol)). ${ }^{6}$

Bentuk rancangan penelitian dapat dilihat pada tabel 1 di bawah ini :

Tabel 1. Bentuk Rancangan One Group pretestPostest

\begin{tabular}{ccc}
\hline Pretest & Perlakuan & Postest \\
\hline $\mathrm{O}_{1}$ & $\mathrm{X}_{\mathrm{a}}$ & $\mathrm{O}_{2}$ \\
\hline $\mathrm{O}_{3}$ & $\mathrm{X}_{\mathrm{b}}$ & $\mathrm{O}_{4}$
\end{tabular}

Keterangan :

$\mathrm{O}_{1}$ : Debris indeks sebelum berkumur dengan obat kumur

$\mathrm{X}_{\mathrm{a}}$ : Perlakuan (Responden berkumur dengan obat kumur)

$\mathrm{O}_{2}$ : Debris indeks setelah diberikan perlakuan dengan obat kumur

O3 : Debris indeks sebelum berkumur dengan air putih
$\mathrm{X}_{\mathrm{b}}$ : Perlakuan (Responden berkumur dengan air putih)

$\mathrm{O}_{4}$ : Debris indeks setelah diberikan perlakuan dengan air putih. ${ }^{6}$

Waktu penelitian dilaksanakan pada bulan Mei 2017. Lokasi penelitian dilaksanakan di kampus Jurusan Keperawatan Gigi Poltekkes Kemenkes Manado.

Populasi dan Sampel :

1. Populasi dalam penelitian Ini adalah seluruh mahasiswa tingkat 1 Jurusan Keperawatan Gigi Poltekkes Kemenkes Manado yang masih aktif

2. Sampel yang digunakan dalam penelitian ini adalah total sampling, yang berjumlah 54 orang dengan kriteria inklusi dibawah ini :

a. Bersedia dijadikan responden

b. Mahasiswa yang masih aktif

c. Mahasiswa yang hadir pada saat akan dilakukan pengambilan sampel penelitian. Dengan menggunakan metode diatas jumlah sampel yang digunakan yaitu jumlah mahasiswa yang bersedia dijadikan responden dan hadir pada saat akan dilakukan penelitian yaitu berjumlah 40 orang mahasiswa.

Variabel Penelitian: Variabel bebas (independent variabel) yaitu obat kumur antiseptic, Variabel terikat (dependent variabel) yaitu debris indeks

\section{Defenisi Operasional}

1. Obat kumur adalah cairan dengan rasa tertentu yang digunakan untuk berkumur setelah menyikat gigi atau flossing gigi. obat kumur yang digunakan adalah merek Listerine, dengan cara pemakaian berkumur sebanyak $20 \mathrm{ml}$ selama 30 detik sebanyak 2 kali sehari dan perlakuan selama 3 hari

2. Debris indeks adalah nilai dari endapan lunak yang terjadi karena adanya sisa-sisa makanan yang melekat pada gigi. Pengukuran dilakukan dengan menjumlahkan seluruh 
sekor kemudian membaginya dengan jumlah sigmen yang diperiksa (Putri dkk, 2010). Dan skor indeks debris yang didapat akan mengikuti ketentuan kriteria sebagai berikut : Baik: jika nilainya antara $0-0,6$, Sedang : jika nilainya antara 0,7 - 1,8, Buruk: jika nilainya antara $1,9-3$.

Jalannya penelitian :

1. Tahap Persiapan: Melakukan survei pendahuluan dan pembuatan izin penelitian.

2. Tahap Pelaksanaan.

1) Pada penelitian ini, peneliti dibantu 4 orang teman yang sudah memahami cara pemeriksaan debris indeks

2) Hari pertama

a. Mahasiswa diminta untuk mengisi formulir pemeriksaan yang meliputi nama, umur, jenis kelamin, alamat dan tanggal pemeriksaan.

b. Mahasiswa dibagi menjadi 2 kelompok yaitu :

1. Mahasiswa berkumur dengan obat kumur dan diberi instruksi untuk berkumur dengan obat kumur sebanyak $20 \mathrm{ml}$ selama 30 detik sebanyak 2 kali sehari dan perlakuan selama 3 hari

2. Mahasiswa berkumur dengan air putih dan diberi instruksi untuk berkumur dengan dengan air putih sebanyak $20 \mathrm{ml}$ selama 30 detik sebanyak 2 kali sehari dan perlakuan selama 3 hari

3.Pemeriksaan debris indeks awal, dilakukan dengan cara dioleskan cairan disclosing solution pada gigi indeks sebelum diberi perlakuan ( berkumur dengan obat kumur ).

3) Hari kedua melakukan pemeriksaan debris indeks sesudah diberi perlakuan ( menggunakan obat kumur hari ke 1)
4) Hari ketiga Pemeriksaan debris indeks sesudah diberi perlakuan (menggunakan obat kumur hari ke 2)

5) Hari keempat melakukan pemeriksaan akhir sesudah perlakuan ( menggunakan obat kumur hari ke 3)

Data yang diperoleh kemudian ditabulasi dan disajikan dalam bentuk tabel yang disertai penjelasan, sedangkan untuk melihat perbedaan debris indeks menggunakan uji paired sample $t$ Test, dengan menggunakan perangkat lunak computer dengan aplikasi statistic SPSS (statistical product and service solution).

\section{HASIL DAN PEMBAHASAN}

\section{HASIL}

Penelitian ini dilakukan pada 30 orang responden (siswa) yang bagi menjadi 2 kelompok dengan karakteristik responden menurut jenis kelamin dan umur.

Tabel.2 Distribusi Frekuensi responden menurut jenis kelamin

\begin{tabular}{ccc}
\hline Jenis Kelamin & Jumlah & \% \\
\hline Laki - laki & 15 & 50 \\
Perempuan & 15 & 50 \\
\hline Total & 30 & 100 \\
\hline
\end{tabular}

Dari tabel.2 menunjukkan persentase jenis kelamin antara laki-laki dan perempuan seimbang yaitu masing-masing $50 \%$

Tabel.3 Distribusi Frekuensi responden menurut umur

\begin{tabular}{ccc}
\hline Umur & Jumlah & \% \\
\hline 9 tahun & 10 & 33.33 \\
10 tahun & 16 & 53.33 \\
11 tahun & 4 & 13.33 \\
\hline Total & 30 & 100 \\
\hline
\end{tabular}


Dari tabel.3 menunjukkan persentase umur yang tertinggi pada umur 10 tahun (53.33\%) dan persentase terendah pada umur 11 tahun $(13.33 \%)$.

\section{Distribusi Responden Sebelum Berkumur Berdasarkan Kriteria Debris Indeks Pada Kelompok Perlakuan dan Kelompok Kontrol}

Distribusi responden sebelum berkumur berdasarkan kriteria debris indeks sebelum berkumur pada kelompok perlakuan dan kelompok kontrol dapat dilihat pada tabel 4 berikut ini :

Tabel 4. Distribusi Responden Sebelum Berkumur Berdasarkan Kriteria Debris Indeks Pada Kelompok Perlakuan dan Kelompok kontrol

\begin{tabular}{lcccc}
\hline \multirow{2}{*}{ Kategori } & \multicolumn{4}{c}{ Debris Indeks } \\
\cline { 2 - 5 } & Baik & Sedang & Buruk & N \\
Kel. & 0 & 14 & 6 & 20 \\
$\begin{array}{l}\text { Perlakuan } \\
\text { Kel. }\end{array}$ & 0 & 15 & 5 & 20 \\
Kontrol & & & & \\
\hline Total & 0 & 29 & 11 & 40 \\
\hline
\end{tabular}

Dari tabel.4 menunjukkan bahwa persentase tertinggi pada kelompok kontrol dengan kriteria debris indeks sedang sebanyak 15 responden .

2. Distribusi Rerata Debris Indeks (DI) Responden Sebelum berkumur pada Kelompok Perlakuan dan Kelompok Kontrol

Distribusi rerata debris indeks (DI) responden sebelum berkumur pada kelompok perlakuan dan kelompok kontrol dapat dilihat pada tabel 5 dibawah ini :

Tabel 5. Distribusi Responden Sebelum Berkumur Pada Kelompok Perlakuan dan Kelompok Kontrol

\begin{tabular}{lcc}
\hline \multicolumn{1}{c}{ Kategori } & Debris Indeks & N \\
\hline Kel. Perlakuan & 1.69 & 20 \\
Kel. Kontrol & 1.66 & 20 \\
\hline \multicolumn{1}{c}{ Total } & & 40 \\
\hline
\end{tabular}

\section{Distribusi Debris Indeks (DI) Responden Sesudah Berkumur pada Kelompok Perlakuan dan Kelompok Kontrol}

Distribusi debris indeks (DI) responden sesudah berkumur pada kelompok perlakuan dan kelompok kontrol dapat dilihat pada tabel 6 berikut ini :

Tabel 6. Distribusi Responden Sesudah Berkumur Pada Kelompok Perlakuan dan Kelompok Kontrol

\begin{tabular}{lccccc}
\hline \multirow{2}{*}{ Kategori } & \multicolumn{5}{c}{$\begin{array}{c}\text { Nilai Rata-Rata Debris Indeks } \\
\text { Sesudah Berkumur }\end{array}$} \\
\cline { 2 - 6 } & P.I & P.II & P.III & Rerata & N \\
\hline Kel. & 1.46 & 1.02 & 0.69 & 1.06 & 20 \\
$\begin{array}{l}\text { Perlakuan } \\
\text { Kel. }\end{array}$ & 1.58 & 1.47 & 1.50 & 1.52 & 20 \\
Kontrol & & & & & \\
\hline Total & & & & & 40 \\
\hline
\end{tabular}

\section{Distribusi Debris Indeks (DI) Responden Sebelum dan Sesudah Berkumur Pada Kelompok Perlakuan dan Kelompok Kontrol}

Distribusi debris indeks (DI) responden sebelum dan sesudah berkumur pada kelompok perlakuan dan kelompok kontrol dapat dilihat pada tabel 7 dibawah ini :

Tabel 7. Distribusi Responden Sesudah Berkumur Pada Kelompok Perlakuan dan Kelompok Kontrol

\begin{tabular}{lccc}
\hline \multirow{2}{*}{ Kategori } & \multicolumn{2}{c}{ Nilai Rata-Rata Debris Indeks } \\
& \multicolumn{2}{c}{ Sebelum dan Sesudah Berkumur } \\
\cline { 2 - 4 } & Sebelum & Sesudah & N \\
\hline Kel. Perlakuan & 1.69 & 1.06 & 20 \\
Kel. Kontrol & 1.66 & 1.52 & 20 \\
\hline Total & \multicolumn{4}{|c}{} \\
\hline
\end{tabular}

5. Analisis Perbedaan Debris Indeks Sebelum dan Sesudah Berkumur Pada Kelompok Perlakuan 
Hasil nilai pemeriksaan debris indeks sebelum dan sesudah diberi perlakuan dianalisis dengan menggunakan uji paired t-Test. Hasil uji perbedaan sebelum dan sudah berkumur terhadap debris indeks dapat dilihat pada tabel 8 dibawah ini :

Tabel 8. Analisis Perbedaan Debris Indeks Sebelum dan Sesudah Berkumur

\begin{tabular}{|c|c|c|c|c|c|c|}
\hline $\begin{array}{c}\text { Sb } \\
\text { Berkumur }\end{array}$ & $\begin{array}{c}\text { Ss } \\
\text { Berkumur }\end{array}$ & Mean & $\begin{array}{c}\text { t } \\
\text { hitung }\end{array}$ & df & $\alpha$ & $p$ \\
\hline 1.6910 & 1.0675 & $\mathbf{0 . 6 2 3 5 0}$ & $\mathbf{1 1 . 9 4 4}$ & 19 & $\mathbf{0 . 0 5}$ & $\mathbf{0 . 0 0 0}$ \\
\hline
\end{tabular}

Berdasarkan hasil analisis perbedaan debris indeks sebelum dan sesudah berkumur memperlihatkan adanya perbedaan nilai rata-rata debris indeks sebelum dan sesudah. Hal ini terlihat pada nilai rata-rata debris indeks sebelum diperoleh sebesar 1.6910, sedangkan nilai ratarata debris indeks sesudah berkumur mengalami penurunan dengan nilai rata-rata yaitu 1.0675. Ini berarti terjadi penurunan debris indeks dengan nilai rata-rata 0.62350 . Berdasarkan hasil analisis dengan menggunakan uji paired sample $t$ Test pada tingkat kemaknaan 95\% $(\alpha=0.05)$, diperoleh nilai $p=0.000(p<0.05)$ dan nilai $\mathrm{t}_{\text {hitung }}$ $=11.944$ dengan $\mathrm{df}=19, \mathrm{t}_{\text {tabel }}=1.729\left(\mathrm{t}_{\text {hitung }}>\mathrm{t}\right.$ tabel).

Maka hal ini berarti ada perbedaan debris indeks sebelum dan sesudah menggunakan obat kumur antiseptik pada mahasiswa tingkat 1 Jurusan Keperawatan Gigi Poltekkes Kemenkes Manado yang bermakna signifikan, sehingga hipotesis $\left(\mathrm{H}_{1}\right)$ dapat diterima, terhadap perbedaan debris indeks sebelum dan sesudah perlakuan.

\section{PEMBAHASAN}

Gigi dan mulut adalah salah satu bagian tubuh manusia terpenting yang diberikan Tuhan kepada manusia. Dengan mulut manusia bisa berkomunikasi dengan yang lain dan dengan gigi dan mulut manusia juga bisa mengonsumsi makanan sebagai sumber energi bagi kehidupan manusia, melalui gigi dan mulut juga bisa memberikan nilai estetika bagi wajah manusia. Oleh karena itu kesehatan gigi dan mulut perlu selalu dipertahankan. ${ }^{7}$

Beberapa masalah kesehatan atau penyakit pada gigi dan mulut dapat terjadi sejak usia bayi hingga lansia. Penyakit tersebut dapat menimbulkan berbagai dampak, mulai dampak yang paling ringan seperti ketidak nyamanan hingga dampak yang berat sepeti tidak bisa makan yang menyebabkan seseorang bisa mengalami gangguan nutrisi, dan terjadinya infeksi yang bisa mengakibatkan penyakitpenyakit lain ditubuh kita. ${ }^{2}$

Cara menjaga kesehatan gigi dapat dilakukan dengan cara. Menyikat gigi minimal 2 kali dalam sehari yaitu pagi sehabis sarapan dan malam sebelum tidur, mangonsumsi buah-buahan yang berserat dan berair, mengurangi makanan yang manis dan melekat pada gigi, serta berkumurkumur menggunakan obat kumur dan memeriksakan gigi secara rutin yaitu setiap 6 bulan sekali walaupun anda tidak merasakan gigi sakit. Hal ini diperlukan agar dokter dapat mendeteksi lubang lubang kecil yang terjadi pada gigi dan dapat di tangani segera agar lubang tidak semakin besar. ${ }^{8}$

Menyikat gigi merupakan proses pembersihan gigi yang rutin dilakukan orang. Sayangnya banyak kuman di daerah sela gigi dan gusi yang tidak dapat dijangkau oleh sikat gigi. Makanya tidak jarang dijumpai orang yang rajin menyikat gigi tapi giginya tetap berlubang dan gusinya tetap meradang. Obat kumur antiseptik dapat mengatasi masalah tersebut dengan cara mengontrol terbentuknya plak gigi dan memperlambat proses maturasi (pematangan). ${ }^{9}$

Penggunaan obat kumur antiseptik membunuh kuman yang tedapat di sela gigi dan gusi sehingga secara nyata dapat mencegah karies (gigi belubang) dan penyakit radang gusi 
(gingivitis). ${ }^{9}$ Salah satu obat kumur merek dagang yang terkenal di masyarakat yaitu antiseptik listerin adalah yang pertama sebagai anti plak dan anti gingivitis obat kumur ini telah disetujui oleh ADA. Dalam penggunaan obat kumur ini, pasien dianjurkan untuk berkumur sehari 2 kali sebanyak $20 \mathrm{ml}$ dan dikumurkan selama 30 detik. Listerin ini telah digunakan sudah lebih dari 110 tahun. Dalam uji klinis jangka panjang, listerin telah terbukti mengurangi akumulasi plak dan keparahan gingivitis hingga $34 \%{ }^{4}$

Plak adalah faktor utama yang menyebabkan timbulnya masalah kesehatan gigi dan mulut. Plak adalah lapisan lunak yang tidak berwarna, tidak dapat di lihat jelas dengan mata dan melekat erat pada permukaan gigi. ${ }^{1}$ Kebersihan gigi dan mulut yang buruk menunjukan banyaknya sisa-sisa makanan (debris) yang melekat pada permukaan gigi. debris mengandung plak, material alba,dan food debris. Kebersihan gigi dan mulut dipengaruhi oleh kebersihan gigi dan mulut. Madel (1974) dan Leo (1967) menyatakan bahwa plak terdiri dari 70\% bakteri dan $30 \%$ bahan matrik antar sel. Bakteri adalah faktor penting dalam etiologi karies gigi. Secara histologis didalam email dan dentin yang mengalami karies gigi menunjukan adanya microorganisme yang bersifat kariogenik seperti golongan streptococci dan lactobacillus yang dapat menyebabkan karies pada gigi. ${ }^{10}$

Berdasarkan data yang diperoleh dalam penelitian yang dilakukan pada bulan Juni 2017 di Poltekkes Kemenkes Manado pada mahasiswa Tingkat 1 Jurusan Keperawatan Gigi yang berjumlah 40 responden, guna untuk mengetahui apakah ada perbedaan debris indek sebelum dan sesudah berkumur dengan obat kumur antiseptik dimana sebelum berkumur pada kelompok perlakuan yaitu dengan nilai rerata 1.69 dan kelompok kontrol dengan rerata yaitu 1.66. Dimana kedua nilai rerata ini dikategorikan kriteria sedang, hal ini disebabkan karenan responden mengabaikan kesehatan gigi dan mulutnya dan tidak mengetahui bahwa hanya dengan menyikat gigi saja tidak bisa menghilangkan sisa makana (debris) yang berada di sela-sela gigi. Oleh sebab itu disarankan untuk menggunakan obat kumur karena selain praktis obat kumur juga bisa menjangkau kesela-sela gigi. $^{9}$

Setelah berkumur pada kelompok perlakuan yaitu didapat nilai dengan rerata 1.06 dan kelompok kontrol didapat nilai rerata 1.52. Penurunan debris indeks terjadi setelah berkumur dengan obat kumur antiseptik, yang memiliki khasiat bagi kesehatan gigi. ${ }^{4}$

Setelah pemeriksaan ditemukan adanya perbedaan nilai debris indeks sebelumdan sesudah. Hal ini terlihat pada nilai rata-rata debris indek sebelum perlakuan diperoleh nilai rata-rata 1.66. Sedangkan nilai debris indeks sesudah mengalami penurunan dengan nilai rata-rata 1.06. Berdasarkan hasil analisis statistik menggunakan uji $t$ pada tingkat kemaknaan 95\% $(\alpha=0.05) p=$ $0.000 \quad(p<0.05)$, sehingga ada pengaruh signifikan antara sebelum berkumur dengan obat kumur antiseptik dan sesudah berkumur dengan obat kumur antiseptik.

Adanya pengaruh yang signifikan terhadap penurunan debris indeks sebelum dan sesudah berkumur dengan obat kumur antiseptik dikarenakan obat kumur antiseptik mempunyai kandungan thymol, mentol, eucaplytol, dan salicylate metil yang termasuk dalam minyak assential yang bersifat antiseptik dan antibakteri yang dapat efektif membunuh kuman dan infeksi dimulut serta melindungi gigi dari plak dan kerusakan

Hasil penelitian ini sejalan dengan dengan penelitian dari (Torar 2013) tentang pengaruh berkumur dengan menggunakan obat kumur terhadap plak indeks pada siswa kelas $1 \mathrm{SMP}$ St HUBERTUS Manado, bahwa obat kumur antiseptik listerin dapat menurunkan plak indeks. $^{11}$ 


\section{KESIMPULAN}

Berdasarkan hasil penelitian yang telah dilaksanakan pada mahasiswa tingkat 1 Jurusan Keperawatan Gigi Poltekkes Kemenkes Manado dapat disimpulkan bahwa berkumur-kumur menggunakan obat kumur antiseptik lebih efektif dibandingkan hanya dengan berkumur-kumur menggunakan aquades. Hal ini dikarenakan kandungan yang ada didalam obat kumur antiseptik termasuk dalam minyak assential bersifat antiseptik dan antibakteri, yang dapat berpengaruh terhadap penurunan debris.

\section{SARAN}

1. Berdasakan hasil penelitian yang didapatkan maka penulis menyarankan untuk selalu menjaga kebersihan gigi dan mulut. Salah satunya adalah dengan menyikat gigi minimal dua kali dalam sehari yaitu pagi setelah sarapan dan malam sebelum tidur, serta teratur berkumur dengan obat kumur yaitu 2 kali dalam sehari setelah menggosok gigi, dan memeriksakan gigi ke klinik gigi minimal 6 bulan sekali

2. Untuk penelitian selanjutnya diharapkan dapat melaksanakan penelitian tentang manfaat obat kumur bagi kesehatan gigi dan mulut dengan meneliti variabel lain yang belum diteliti.

\section{DAFTAR PUSTAKA}

1. Ircham, Ediati, S., Sidarto, S. (1993). Penyakit-Penyakit Gigi Dan Mulut Pencegahan Dan Perawatannya. Liberty. Yogyakarta.

2. Putri, M.H., Herijulianti, E., Nurjannah, N. (2010). Ilmu Pencegahan Penyakit Jaringan Keras dan Jaringan Pendukung Gigi. Buku Kedokteran Gigi EGC. Jakarta

3. Bararah,V. (2012). Apakah Obat Kumur Penting Digunakan. http://health.detik.com/read/2012/11/26/1155 44/2101252/766/apakah-obat-kumur-pentingdigunakan. Diakses selasa 12 feb 2013

4. Harris, N.O,. Godoy, F.G. 2004. Primary Preventive Dentistry Sixth Edition. Pearson Prentice, New Jersey

5. Sriyono, N.W. (2005). Pengantar Ilmu Kedokteran Gigi Pencegahan. MedikaFakultas Kedokteran UGM. Yogyakarta

6. Notoatmodjo, S. (2002). Metode Penelitian Kesehatan. Rineke cipta. Jakarta.

7. Margareta, S. (2012). 101 tips \& terapi alami agar gigi putih \& sehat. Pustaka Cerdas. Yogyakarta.

8. Irma , I. dan Intan, A.(2013). Penyakit mulut dan THT. Nuha Medi ka. Yogyakarta.S

9. Ghofur, A. (2012). Buku Pintar Kesehatan Gigi dan Mulut. Mitra Buku. Yogyakarta

10. Bahar, A. (2011). Paradigma Baru Pencegahan Karies Gigi. Fakultas Ekono mi Universitas Indonesia. Jakarta.

11. Torar, C.J. (2013). Pengaruh Berkumur Dengan Menggunakan Obat Kumur Terhadap Plak Indeks Pada Siswa Kelas 1 St Hubertus Manado.KTI Jurusan Keperawatan Gigi Politeknik Kesehatan Kementrian kesehatan, Manado 